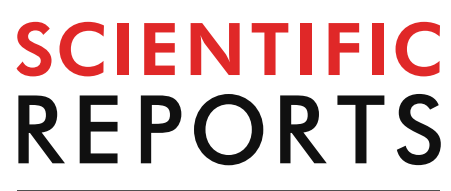

natureresearch

Check for updates

\title{
A novel humanized mouse model to study the function of human cutaneous memory $T$ cells in vivo in human skin
}

Maria M. Klicznik ${ }^{1}$, Ariane Benedetti ${ }^{1}$, Laura M. Gail ${ }^{1}$, Suraj R. Varkhande ${ }^{1}{ }^{1}$, Raimund Holly ${ }^{1}$, Martin Laimer ${ }^{2}$, Angelika Stoecklinger ${ }^{1}$, Andreas Sir $^{3}$, Roland Reitsamer ${ }^{3}$, Theresa Neuper ${ }^{1}$, Jutta Horejs-Hoeck ${ }^{\circledR 1}$, Michael D. Rosenblum ${ }^{4}$, Daniel J. Campbell ${ }^{5,6}$, Eva M. Murauer ${ }^{7}$ \& Iris K. Gratz $11,5,7 \bowtie$

Human skin contains a population of memory T cells that supports tissue homeostasis and provides protective immunity. The study of human memory $T$ cells is often restricted to in vitro studies and to human PBMC serving as primary cell source. Because the tissue environment impacts the phenotype and function of memory T cells, it is crucial to study these cells within their tissue. Here we utilized immunodeficient NOD-scid IL2ry ${ }^{\text {null }}$ (NSG) mice that carried in vivo-generated engineered human skin (ES). ES was generated from human keratinocytes and fibroblasts and was initially devoid of skinresident immune cells. Upon adoptive transfer of human PBMC, this reductionist system allowed us to study human $\mathrm{T}$ cell recruitment from a circulating pool of $\mathrm{T}$ cells into non-inflamed human skin in vivo. Circulating human memory T cells preferentially infiltrated ES and showed diverse functional profiles of T cells found in fresh human skin. The chemokine and cytokine microenvironment of ES closely resembled that of non-inflamed human skin. Upon entering the EST cells assumed a resident memory $T$ cell-like phenotype in the absence of infection, and a proportion of these cutaneous $T$ cells can be locally activated upon injection of monocyte derived dendritic cells (moDCs) that presented Candida albicans. Interestingly, we found that $\mathrm{CD} 69^{+}$memory T cells produced higher levels of effector cytokines in response to Candida albicans, compared to CD69. T cells. Overall, this model has broad utility in many areas of human skin immunology research, including the study of immune-mediated skin diseases.

As the body's outermost barrier, the skin represents a unique and complex immunological organ. As such, healthy human skin contains a large number of $\mathrm{CD} 45 \mathrm{RO}^{+}$memory $\mathrm{T}$ cells ${ }^{1,2}$ that support tissue homeostasis and ensure an adequate response to pathogen $s^{3-5}$. A population of resident memory $\mathrm{T}\left(\mathrm{T}_{\mathrm{RM}}\right)$ cells is found within most tissues where it remains long-term and provides protective immunity after $\mathrm{T}_{\mathrm{RM}}$ differentiation in response to primary infection ${ }^{6,7}$. Additionally, $\mathrm{T}_{\mathrm{RM}}$ may have a protective function in organ transplantation ${ }^{8}$ and support immunosurveillance against melanoma ${ }^{9}$. Cutaneous memory $\mathrm{T}$ cells have also been implicated in several diseases, such as cutaneous $\mathrm{T}$ cell lymphoma specifically mycosis fungoides ${ }^{10,11}$.

Generation and maintenance of memory T cells have been extensively studied using murine models ${ }^{12,13,13-16}$, and significant advances in understanding the role of the skin microenvironment on T cell function and memory development in murine skin have been made ${ }^{15,17,18}$. Since $\mathrm{T}$ cell responses are strongly influenced by the surrounding tissue $\mathrm{e}^{19,20}$, and T cells show site-specific functional and metabolic properties ${ }^{18,21}$, it is crucial to

\footnotetext{
${ }^{1}$ Department of Biosciences, University of Salzburg, Salzburg, Austria. ${ }^{2}$ Department of Dermatology, University Hospital Salzburg, Paracelsus Medical University Salzburg, Salzburg, Austria. ${ }^{3}$ Breast Center, University Hospital Salzburg, Paracelsus Medical University Salzburg, Salzburg, Austria. ${ }^{4}$ Department of Dermatology, University of California, San Francisco, CA 94143, USA. ${ }^{5}$ Benaroya Research Institute, 1201 9th AVE, Seattle, WA 98101, USA. ${ }^{6}$ Department of Immunology, University of Washington School of Medicine, Seattle, WA 98109, USA. ${ }^{7}$ EB House Austria, Department of Dermatology, University Hospital of the Paracelsus Medical University Salzburg, Salzburg, Austria. ${ }^{\bowtie}$ email: iris.gratz@sbg.ac.at
} 
study cutaneous immunity within its physiological compartment in vivo. However, direct translation from the murine cutaneous immune system is complicated by fundamental structural differences, as well as a lack of direct correspondence between human and murine immune cell populations ${ }^{4,22-24}$. Due to technical and ethical limitations, studies of human memory $\mathrm{T}$ cell generation have mostly been restricted to ex vivo analyses and in vitro experiments, and the specific contribution of keratinocyte- and fibroblast-derived signals to cutaneous immunity in human skin remains poorly understood. A better understanding of the requirements of human cutaneous memory $\mathrm{T}$ cell recruitment and maintenance in human skin could lead to novel therapies for $\mathrm{T}$ cell mediated inflammatory diseases. However, currently existing human immune system (HIS) animal models or skin-xenograft models are complicated by unavoidable inflammation or allo-reactivity. Thus suitable in vivo models are required, that faithfully replicate conditions found in human skin under homeostatic conditions to study the requirements for the recruitment and the generation of human cutaneous memory $\mathrm{T}$ cell generation and their function in vivo.

Skin humanized mice in which immunodeficient mice receive skin grafts from either healthy donors or patients with skin diseases and human peripheral blood mononuclear cells (PBMC) ${ }^{25-27}$ are currently used to study human inflammatory skin conditions in vivo, such as the rejection of skin allografts and xenogeneic graft versus host disease (GvHD) development ${ }^{28}$. However, studies of $\mathrm{T}$ cell recruitment to the skin tissue in absence of inflammation and antigen-specific activation of cutaneous $\mathrm{T}$ cells has been much harder to establish. Additionally, skin samples obtained from adult donors contain resident immune cells and have a high degree of heterogeneity in terms of immune cell infiltration ${ }^{2,25,28,29}$, making it difficult to functionally analyze and manipulate discrete skin-tropic $\mathrm{T}$ cell populations upon xenografting.

To reduce the heterogeneity found in human skin transplants, bioengineered skin or composite skin grafts were used to study the pathogenesis of inflammatory diseases, such as psoriasis or atopic dermatitis ${ }^{30,31}$. In these, a sheet of keratinocytes was layered over an in vitro generated dermis generated within a fibrinogen or collagen matrix ${ }^{32-34}$. However, in these models immune cells were applied locally within the engineered skin graft and recruitment of skin-tropic T cells was not studied. Importantly, data obtained in mouse studies suggested that local skin infection can lead to seeding of the entire cutaneous surface with long lived, highly protective tissueresident memory T cells, although the highest concentration of these cells occurred at the site of infection ${ }^{35}$. Repeated re-infections lead to progressive accumulation of highly protective tissue-resident memory cells in non-involved $\operatorname{skin}^{36}$.

Recruitment of human skin-tropic T cells into non-inflamed and inflamed skin is facilitated by several chemokines and cytokines secreted by keratinocytes and fibroblasts ${ }^{37-39}$. Here we generated a humanized skin mouse model where we utilized mice with human skin engineered only from keratinocytes and fibroblasts to create a reductionist system to study human $\mathrm{T}$ cell recruitment to the skin and function within human skin in absence of acute inflammation. Specifically, we used NOD-scid IL2ry null (NSG) mice that carried in vivogenerated engineered skin (ES) and received human PBMC. This model enabled us to characterize phenotypic changes of circulating memory $\mathrm{T}$ cells upon entry of the skin as well as locally restricted antimicrobial responses of human cutaneous memory $\mathrm{T}$ cells in absence of infection or inflammation. Additionally, this model offers a new tool to dissect the role of the skin microenvironment in skin immunity in vivo.

\section{Results}

Human T cells specifically infiltrate human engineered skin in a xenograft mouse model. To characterize human $\mathrm{T}$ cell recruitment into the human skin in vivo, we generated engineered skin (ES) from human keratinocytes and fibroblasts that were isolated from healthy human skin, immortalized and expanded in vitro ${ }^{40}$. ES were generated by placing these keratinocytes and fibroblasts in a grafting chamber as described before $^{41}$ and allowed to heal and differentiate for a minimum of 30 days (Fig. 1a). Consistent with the thorough characterization of the ES by Wang et al. ${ }^{41}$, Haematoxilin and Eosin (H\&E) staining showed that the morphology of the ES was similar to that of normal human skin with an epidermal top layer and an underlying dermal layer (Fig. 1b). The epidermal architecture appeared multilayered and stratified, including a stratum basale, stratum spinosum, stratum granulosum and the stratum corneum, seen as flaking cells in the H\&E staining (Fig. 1b, top panel). Human type VII collagen (C7) forms a typical staining-band at the basement membrane zone (BMZ) in immunofluorescence ${ }^{42}$, which we detected in both primary human skin and the ES but not murine skin. This indicated correct separation of dermis and epidermis of the in vivo generated skin (Fig. 1b, middle panel). Staining for human cytokeratin 5/6 showed that expression is highest within the stratum basale, in line with the distinct differentiation status of keratinocytes within the epidermal layers of human skin (Fig. 1b, bottom panel).

After complete wound healing of the ES, skin-donor-matched PBMC that were isolated and stored in liquid nitrogen until use were adoptively transferred, thus creating a mouse model with a human immune system and ES that we designated huPBMC-ES-NSG (Fig. 1a). In previous studies development of xenogeneic GvHD occurred around 5 weeks after adoptive transfer of $10^{7}$ human PBMC into NSG mice ${ }^{43,44}$. To delay the development of GvHD we reduced cell numbers to $1.8-3 \times 10^{6} /$ mouse. The weight of experimental mice was monitored throughout the experiments to monitor potential GvHD development. Although we detected no weight loss over a period of up to 87 days following adoptive transfer of 2.5-3 $\times 10^{6}$ PBMC (Fig. S1), we limited all experiments to approximately 35 days after PBMC transfer to avoid any potential convoluting effects on our studies.

Following adoptive transfer, we monitored immune cell engraftment in the ES and the spleen, which serves as the main peripheral lymphoid organ in NSG mice which lack lymph nodes ${ }^{45}$. Human CD $45^{+}$cells were detectable in the spleen after 14 days and in the ES after 21 days (Fig. 1c,d). After a period of 18-34 days mean levels of human $\mathrm{CD} 45^{+}$cells in spleen and ES were at $>18 \%$ (Fig. 1e, full gating strategy Fig. S2). The majority of human cells $(>94 \%)$ in spleen and ES were $\mathrm{CD}^{+} \mathrm{T}$ cells (Fig. 1f) and the infiltration of human ES by human $\mathrm{CD}^{+}$ cells was significantly higher compared to adjacent murine skin (Fig. 1g). CD $4^{+}$and $\mathrm{CD} 8^{+}$as well as TCR $\gamma \delta^{+} \mathrm{T}$ 
cells engrafted within the spleen and ES at levels comparable to the respective human tissues, PBMC and skin (Fig. 1h,i). The fractions of $\mathrm{CD}^{+}$and $\mathrm{CD}^{+} \mathrm{T}$ cells in spleen and ES reflected the physiological fractions found in human PBMC and skin, respectively (Fig. 1j). This preservation of physiological ratios suggested a specific recruitment process or maintenance mechanism within the ES, similar to human skin. Indeed, T cell-trophic chemokines CCL2 ${ }^{46}, \mathrm{CCL}^{47}$, CXCL10 ${ }^{48}$, CXCL12 $2^{49}$, which support the recruitment of human T cells into human $\operatorname{skin}^{50}$, are secreted within the ES at levels comparable to those of healthy human skin (Fig. 2a).

However, levels of pro-inflammatory cytokines within the ES were equal or even lower than those found in healthy human skin (Fig. 2b), while murine skin lacks these key human chemokines and cytokines. The fact that pro-inflammatory cytokines were not found at increased levels in the ES suggest the absence of acute inflammation within the engineered tissue. Hence it is unlikely that the preferential infiltration of the human ES over murine skin by human T cells (Fig. $1 \mathrm{~g}$ ) is driven by acute inflammation within the ES, but rather due to the physiological environment within the ES that promotes $\mathrm{T}$ cell recruitment and maintenance.

Engrafted T cells share a skin-homing memory-like phenotype. Since a large proportion of T cells in human skin are memory $\mathrm{T}$ cells ${ }^{2,25}$, we assessed whether this was true for ES-infiltrating $\mathrm{CD} 4^{+}$and $\mathrm{CD} 8^{+} \mathrm{T}$ cells (Fig. 3 and Fig. S3). Confirming previous studies of PBMC engraftment in NSG mice, we found that human $\mathrm{CD}^{+}$as well as $\mathrm{CD} 8^{+} \mathrm{T}$ cells isolated from spleens of huPBMC mice did not express markers of naïve $\mathrm{T}$ cells such as CCR7 and CD45RA despite being present in the ingoing PBMC population ${ }^{43}$, and the vast majority of T cells within the ES had also assumed a CCR7 ${ }^{-}$and CD45RA ${ }^{-}$memory phenotype (Fig. 3a and Fig. S3a). Similar to the transferred PBMC, the spleen contained $\mathrm{CD} 4^{+}$and $\mathrm{CD} 8^{+} \mathrm{T}$ cells that expressed cutaneous leukocyte antigen (CLA), a glycan moiety that promotes skin-homing ${ }^{2}$. Consistent with this, $\mathrm{CLA}^{+} \mathrm{T}$ cells accumulate within human skin ${ }^{2}$ and these cells were also significantly enriched in the ES compared to spleen (Fig. $3 \mathrm{~b}$ and Fig. S3b). This indicates preferential recruitment or maintenance of skin-tropic memory $\mathrm{T}$ cells within the ES. In line with this, IL7 and IL15, two cytokines that support memory T cell function and maintenance in human $\operatorname{skin}^{51-53}$, were found at equal levels within the ES and healthy human skin (Fig. 3c). Upon entering the ES, both $\mathrm{CD}^{+}$and $\mathrm{CD} 8^{+} \mathrm{T}$ cells upregulated CD69 expression (Fig. 3d,e and Fig. S3c,d), a marker closely associated with tissue residency of human skin $\mathrm{T}$ cells ${ }^{25}$. Interestingly, this was more pronounced within the $\mathrm{CD} 4^{+}$compared to the $\mathrm{CD}^{+} \mathrm{T}$ cell population. Consistent with CD69 expression, these skin-homing CLA ${ }^{+} \mathrm{T}$ cells expressed CCR6 a chemokine receptor characteristic for tissue-resident memory cells ${ }^{54}$ (Fig. 3d,f and Fig. S3c,e). Additionally, a small fraction of cutaneous T cells also expressed CD103 (Fig. 3g,h and Fig. S3f,g), another marker of human skin $\mathrm{T}_{\mathrm{RM}}{ }^{25}$. It remains to be determined whether these $\mathrm{T}_{\mathrm{RM}}$-like cells are truly resident and maintained long-term or transiently upregulated markers of tissue residency. By contrast, circulating CD62 $\mathrm{L}^{+}$memory T cells could be identified in both spleen and ES among both T cell subsets, representing central memory T cells. (Fig. 3i,j and Fig. S3h, i). Taken together these data indicate that upon entry into the ES, circulating CD4 ${ }^{+}$and $\mathrm{CD} 8^{+} \mathrm{T}$ cells reconstitute a skin-tropic T cell population and assume a memory-like phenotype within the ES.

Cutaneous and splenic T cells from hUPBMC-ES-NSG mice display multifunctional profiles of T cells in human skin and blood. Next, we sought to determine whether the diverse functional phenotypes of human memory $\mathrm{T}$ cells were maintained within the model and thus would be suitable to study human T cell function within human skin in vivo. We assessed the function of splenic and ES-derived T cells following ex vivo stimulation and intracellular cytokine staining. The ability to produce the effector cytokines associated with Th2, Th17 and Th22, IL13, IL17 and IL22, respectively, were preserved in CD4 ${ }^{+} \mathrm{T}$ cells isolated from the huPBMCES-NSG mouse when compared to T cells from human blood and skin (Fig. 4a,b,d-f). By contrast, increased percentages of $\mathrm{CD}^{+} \mathrm{T}$ cells isolated from the spleen and ES produced GM-CSF (Fig. 4c,g). Interestingly while IFN $\gamma^{+} \mathrm{CD}^{+}$cells were increased in the spleen when compared to PBMC, the proportion of IFN $\gamma$-producing $\mathrm{CD} 4^{+}$cells within the ES was comparable to skin from healthy donors (Fig. 4c, h).

The cytokine profiles of $\mathrm{CD} 8^{+} \mathrm{T}$ cells in ES and spleen were comparable to healthy human skin and PBMC with the exception of GM-CSF (Fig. S4d), which was increased within the ES, similar to the $\mathrm{CD} 4^{+} \mathrm{T}$ cell population. This increased production of GM-CSF might be a result of xenogeneic T cell activation within the model ${ }^{55,56}$.

In summary, upon entering the ES, T cells derived from human blood assume the surface phenotype (Fig. 3 and Fig. S3) and the functional profile (Fig. 4 and Fig S4) of cutaneous T cells found within human skin.

Cutaneous $\mathrm{CD}^{+} \mathrm{T}$ cells are locally activated by microbial antigen. Skin $\mathrm{CD} 4^{+} \mathrm{T}$ cells play a crucial role in controlling cutaneous microbes ${ }^{57}$. Particularly, the specific role of $\mathrm{CD}^{+} \mathrm{T}$ cells in responses against the commensal fungus Candida albicans (C.albicans) is underscored by the fact that primary and acquired immunodeficiencies that lead to the impairment of $\mathrm{CD} 4^{+} \mathrm{T}$ cell immunity can cause pathogenic C.albicans infections ${ }^{58-62}$. Consistent with that, the human circulating $\mathrm{T}$ cell pool contains skin-tropic C.albicans-specific memory $\mathrm{T}$ cells ${ }^{63,64}$. Hence we hypothesized that C.albicans-specific memory T cells would be present among the adoptively transferred human PBMC and we chose to assess the functionality of these $\mathrm{T}$ cells in vivo.

To evaluate whether a detectable population of C.albicans-specific $\mathrm{CD} 4^{+}$memory $\mathrm{T}$ cells was indeed present in the human PBMC used for adoptive transfer, we co-cultured donor PBMC for 7 days with autologous monocyte derived dendritic cells (moDCs) that were loaded with heat killed C.albicans (HKCA) because C.albicans specific $\mathrm{T}$ cell responses depend on the presence of $\mathrm{HLA}-\mathrm{DR}^{+} \mathrm{APC}^{16,63}$. Indeed, we found antigen-specific proliferation, activation and cytokine secretion by HKCA stimulated $\mathrm{CD} 4^{+} \mathrm{T}$ cells when compared to co-cultures of PBMC with non-activated or LPS activated moDCs (Fig. S5).

Next, we aimed to assess whether this C.albicans-specific $\mathrm{CD} 4^{+}$memory population would infiltrate the ES and mount a local antigen-specific memory $\mathrm{T}$ cell response upon encounter of microbial antigen. However, consistent with previous reports we found poor engraftment of $\mathrm{HLA}-\mathrm{DR}^{+} \mathrm{CD} 3^{-}$antigen presenting cells (APC) 
a

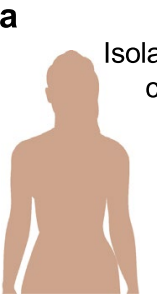

huFib olate skin cells huKc

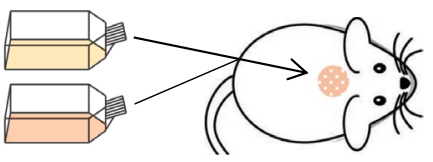

Expand cells

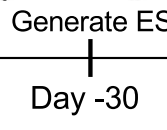

\section{.}

ES healing /
differentiation

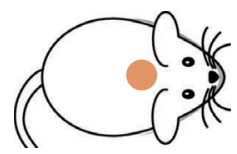

huPBMC-ES-NSG

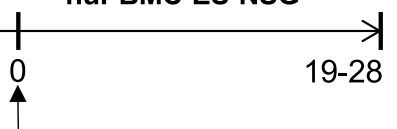

Analysis of spleen and ES

Isolate \& freeze huPBMC

b
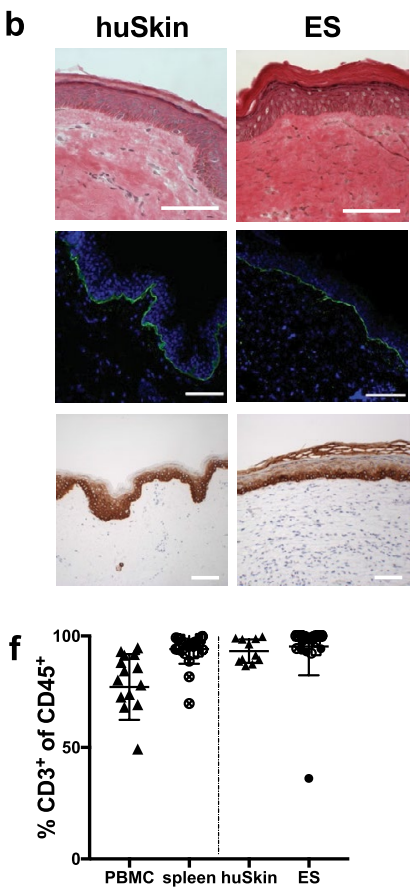

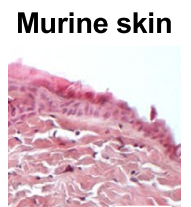

H\&E

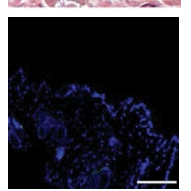

Cytokeratin 5/6 $\rightarrow$ Thaw \& transfer huPBMC
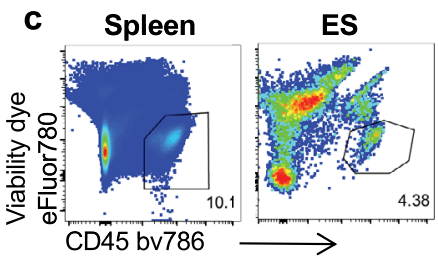

a-hum. type

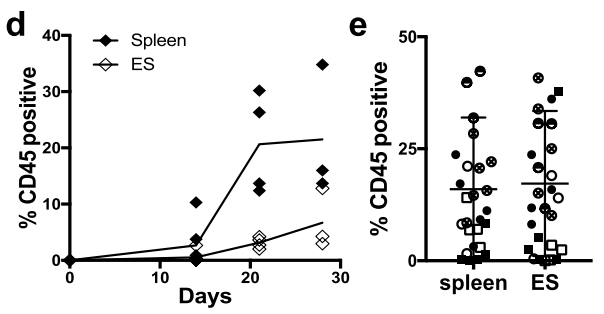

VII collagen
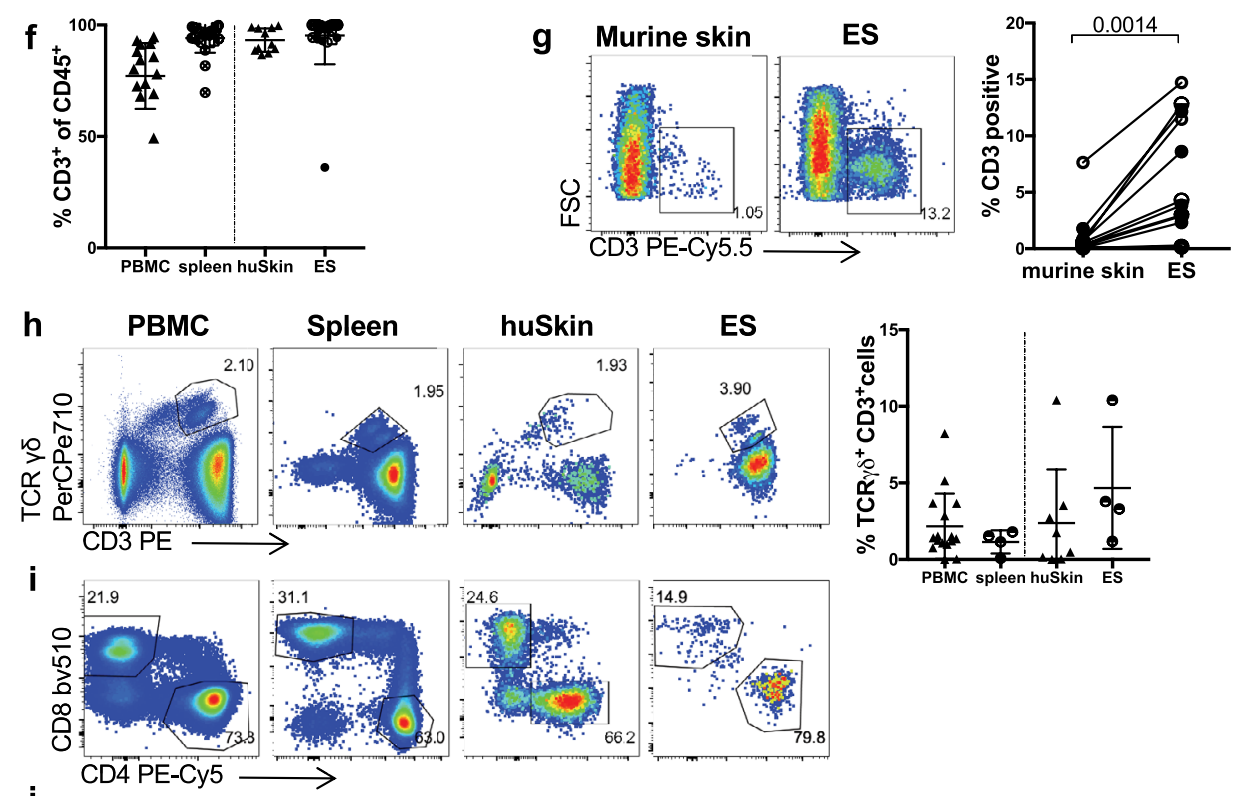

j

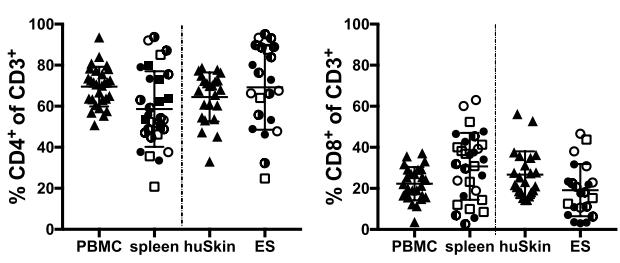

Figure 1. Engineered human skin is preferentially infiltrated by human T cells. (a) Schematic of the huPBMCES-NSG model. (b) ES were generated as in (a) and analyzed by H\&E staining and immunofluorescence staining of human type VII collagen on day 72 (upper two panels) as well as immunohistochemical staining of human Cytokeratin 5/6 in ES (lower panel). Murine skin and human skin from a HD served as controls. White bar $=100 \mu \mathrm{m}(\mathbf{c}-\mathbf{g})$ Single cell suspensions of spleen and ES of huPBMC-ES-NSG mice were analyzed by flow cytometry. Each data point represents an individual human donor or experimental mouse. Circles represent data collected from huPBMC-ES-NSG mice using tissue of donor WT85 (female) and squares donor WT70 (male). The different fillings of the symbols indicate independent experiments. (c) Representative flow cytometry 
analysis and (d) graphical summary of proportion of human $\mathrm{CD}_{4} 5^{+}$cell as $\%$ of live cells in the lymphocyte gate in paired spleen and ES at indicated time points after adoptive transfer of $2.5 \times 10^{6} \mathrm{PBMC}$. (e) Graphical summary of proportion of CD $45^{+}$cells of live cells in spleen and ES 18-34 days after PBMC transfer. $n=3-6 /$ experiment; cumulative data of 6 independent experiments. (f) Graphical summary of the proportion of $\mathrm{CD}^{+}$ cells of live $\mathrm{CD}_{4} 5^{+}$cells 18-35 days after PBMC transfer; $n=3-6$ /experiment; cumulative data of 6 independent experiments. (g) Representative flow cytometry analysis and graphical summary of $\mathrm{CD} 3^{+}$percentages in ES and adjacent murine skin 18-35 days after PBMC transfer gated on live lymphocytes. $\mathrm{n}=3$-6/experiment; cumulative data of 3 independent experiments. Significance determined by paired student's $t$ test; mean \pm SD. (h) Representative plots and graphical summary of $\mathrm{TCR} \gamma \delta^{+}$and $\mathrm{CD}^{+}$cells of live $\mathrm{CD} 45^{+}$in indicated tissues. (i) Representative flow cytometry plots of $\mathrm{CD} 4^{+}$and $\mathrm{CD} 8^{+}$of $\mathrm{CD} 3^{+} \mathrm{CD} 45^{+}$live gated cells (j) Graphical summary of CD4 and CD8 expressing cells in human PBMC and skin and spleen and ES, 18-35 days after PBMC transfer gated on live $\mathrm{CD}^{+} \mathrm{CD} 45^{+}$lymphocytes. $\mathrm{n}=3-6 /$ experiment; Combined data of 6 independent experiments.
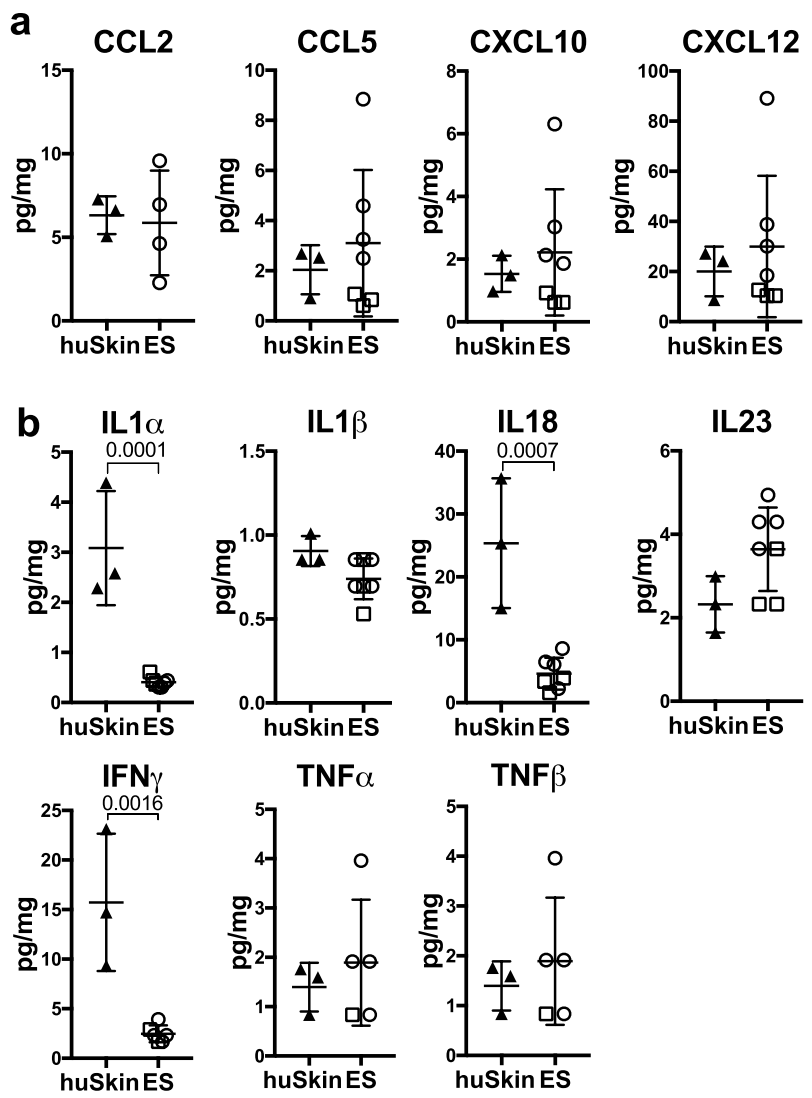

TNF $\alpha$
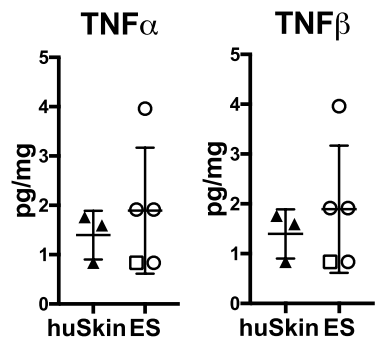

Figure 2. Engineered human skin mirrors chemokine and cytokine levels of non-inflamed human skin. Cytokine and chemokine expression within tissues was determined by bead-based multicomponent analysis of ES from huPBMC-ES-NSG 21 days after PBMC transfer and 3 different healthy human skin donors. Amount of the indicated (a) chemokines and (b) cytokines per mg skin. Statistical significance determined by student's $t$ test; mean $\pm \mathrm{SD}$.

within the NSG mice ${ }^{26}$ both in the spleen and ES (Fig. S6). We further found that injection of HKCA alone into the ES had no impact on T cell proliferation or numbers within the ES (Fig. S7). Thus, to compensate for this lack of APC we pulsed autologous moDCs with HKCA (HKCA/moDC) and injected these intradermally into the ES. LPS activated moDC (LPS/moDC) served as a control for non-C.albicans-specific activation of T cells by activated APCs. Injections were repeated 3 times within 7 days and ES and spleen were analyzed by flow cytometry one week after the last injection (Fig. 5a). Whereas the proportion of human CD $45^{+}$cells in the spleen remained unaffected irrespective of the treatment, a slight increase in the percentage of human $\mathrm{CD}^{+} 5^{+}$ cells could be detected in ES injected with HKCA/moDC compared to LPS/moDC injected ES (Fig. 5b). Additionally, a significantly increased proportion of cutaneous $\mathrm{CD} 4^{+} \mathrm{T}$ cells expressed the proliferation marker Ki67 and upregulated $\mathrm{CD} 25$ upon injection of $\mathrm{HKCA} / \mathrm{moDC}$, indicating activation of $\mathrm{CD} 4{ }^{+} \mathrm{T}$ cells in response to the encountered antigen (Fig. 5c). Similarly, CD4 ${ }^{+} \mathrm{T}$ cells from ES injected with HKCA/moDC produced significantly higher levels of the effector cytokines IL17 and TNFa after ex vivo PMA/Ionomycin stimulation compared to ES that had received LPS/moDC (Fig. 5d). Importantly, the increased proliferation of CD4 ${ }^{+} \mathrm{T}$ cells in response to antigen was locally restricted to the injected ES and absent in splenic T cells (Fig. S7c). 
a

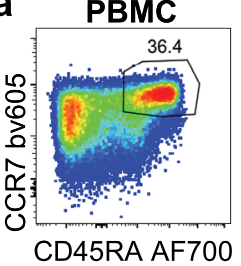

b

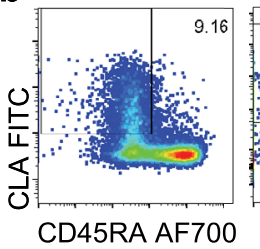

Spleen
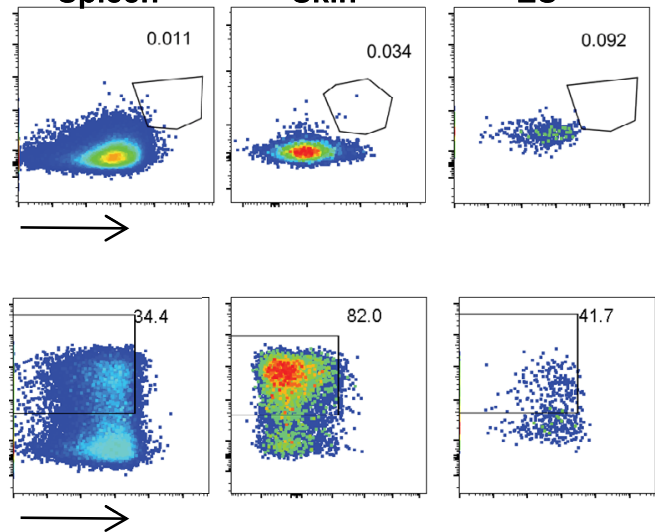

Skin
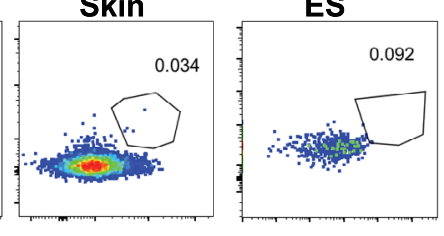

\section{高}

C

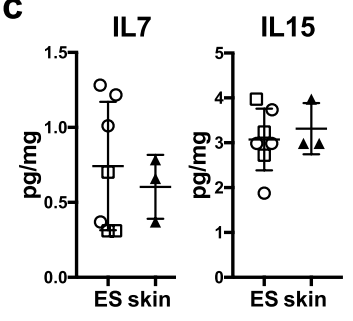

d
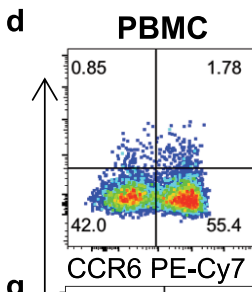

g

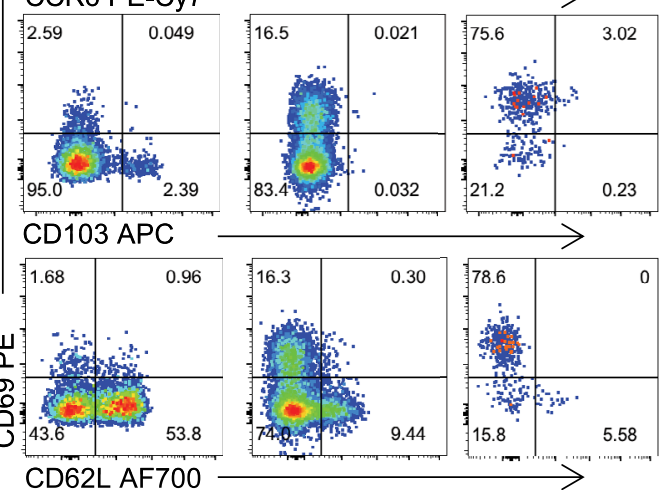

Spleen

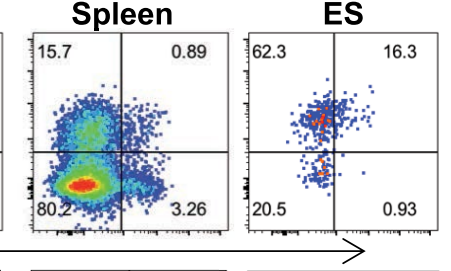

高
CD62L AF700

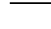
Figure 3. Skin and spleen infiltrating $\mathrm{CD}^{+} \mathrm{T}$ cells show skin-homing memory phenotype and upregulate
markers of tissue residency and skin-tropism in ES. Representative flow cytometry analysis of (a) CCR7 and CD45RA expression, and (b) CLA and CD45RA expression by gated CD $4{ }^{+} \mathrm{CD} 3^{+} \mathrm{CD} 45^{+}$live leukocytes from blood and skin of healthy donors, spleen and ES of huPBMC-ES-NSG mice and graphical summary of the proportions of indicated cells by gated $\mathrm{CD} 4{ }^{+} \mathrm{CD} 3^{+} \mathrm{CD} 45^{+}$live leukocytes. $n=5-6 /$ experiment; cumulative data of 2 independent experiments. (c) Amount of the indicated cytokines per mg skin determined by beadbased multicomponent analysis of ES from huPBMC-ES-NSG and 3 different healthy human skin donors. $(\mathbf{d}, \mathbf{g}, \mathbf{h})$ Representative flow cytometry analysis of the expression of (d) CCR6 and CD69; (g) CD62L and (h) $\mathrm{CD} 103$ in indicated tissues by $\mathrm{CLA}^{+} \mathrm{CD} 45 \mathrm{RA}^{-} \mathrm{CD} 4^{+} \mathrm{CD} 3^{+}$living cells. $(\mathbf{e}, \mathbf{f}, \mathbf{i}, \mathbf{j})$ Graphical summary of $\mathrm{CLA}^{+} \mathrm{CD} 45 \mathrm{RA}^{-} \mathrm{CD}^{+} \mathrm{CD}^{+}$living cells isolated from spleen and $\mathrm{ES}$, expressing the indicated markers. $\mathrm{n}=5$; Significance determined by paired student's $t$ test; mean \pm SD. 
a
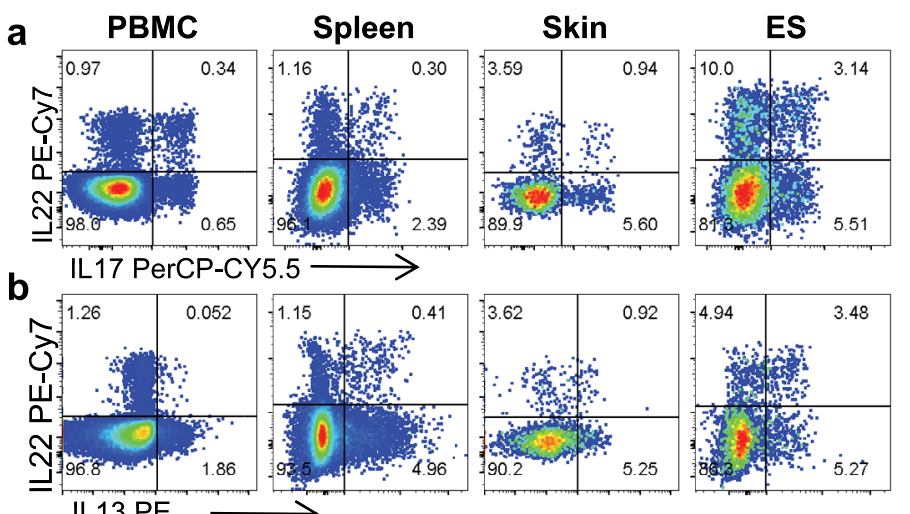

$\mathrm{IL} 13 \mathrm{PE} \longrightarrow$
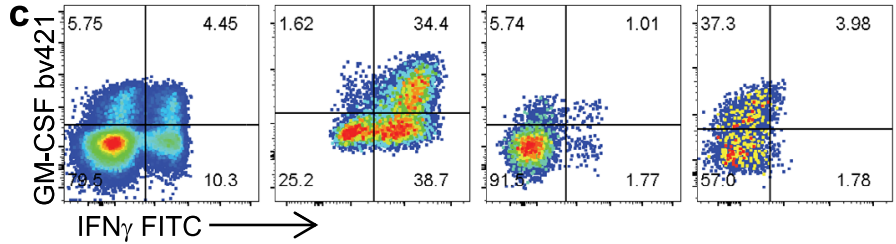

d
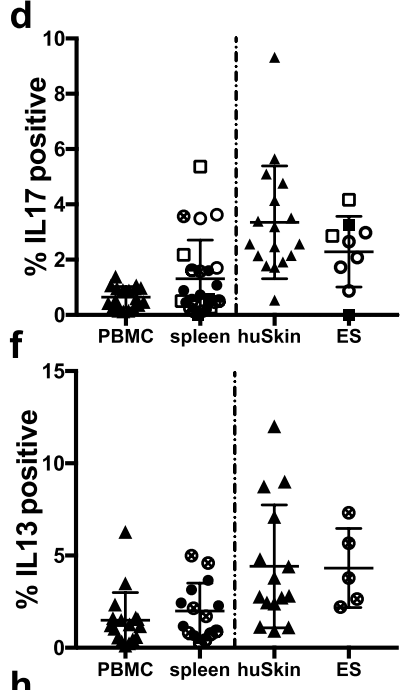

h

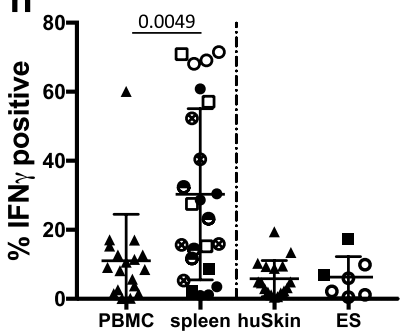

e
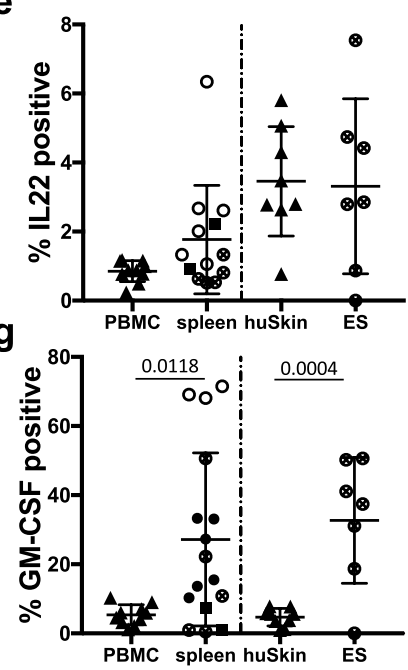

Figure 4. Engrafted splenic and cutaneous human $\mathrm{CD} 4^{+} \mathrm{T}$ cells reflect diverse phenotypes of $\mathrm{T}$ cells in human tissues $(\mathrm{a}-\mathrm{c})$ Single cell suspensions of blood and skin of healthy donors, and spleen and ES of huPBMCES-NSG mice prepared 18-35 days after PBMC transfer, were stimulated ex vivo with PMA/ionomycin and intracellular cytokine production was analyzed by flow cytometry. Representative analysis of IL17, IL22, IL13, GM-CSF and IFN $\gamma \%$ of CD $4^{+}$T cells as indicated. (d-h) Graphical summary of the expression of the indicated cytokines by T cells from blood and skin of healthy donors, and spleen and ES of huPBMC-ES-NSG mice analyzed 18-35 days after PBMC transfer by gated $\mathrm{CD} 4{ }^{+} \mathrm{CD} 3{ }^{+} \mathrm{CD} 45^{+}$live leukocytes. $\mathrm{n}=3-6$ /experiment; cumulative data of $2-5$ independent experiments as indicated by the symbol fillings; each symbol shape is representative of a skin donor (circles = donor WT85 and squares $=$ donor WT70), and each filling represents an independent experiment. 
a
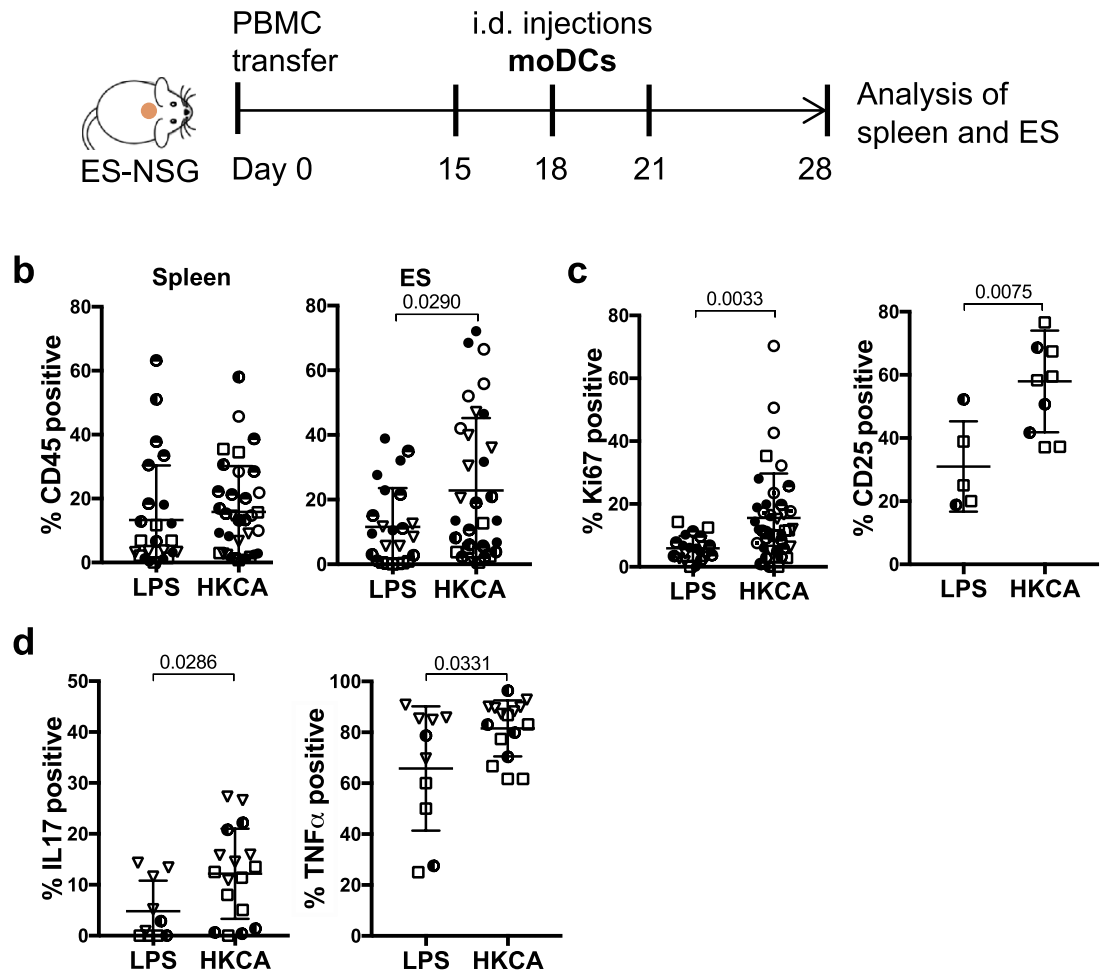

Figure 5. Cutaneous $\mathrm{CD} 4^{+} \mathrm{T}$ cells are activated by local C.albicans presented by moDCs in ES. (a) Schematic outline of the experiment. (b) Graphical summary of the proportion of $\mathrm{CD} 45^{+}$cells among live cells in the lymphocyte gate in indicated organs of huPBMC-ES-NSG mice that received either LPS/moDC injections or HKCA/moDC injections into the ES. $n=2-7 /$ experiment, cumulative data of 6 independent experiments. (c) Graphical analysis of the proportion of Ki67 $7^{+}$proliferating cells and $\mathrm{CD} 25^{+}$cells by gated $\mathrm{CD} 4{ }^{+} \mathrm{CD} 3^{+} \mathrm{CD} 45^{+}$live leukocytes from LPS/moDC or HKCA/moDC treated ES. (c) Single cell suspensions of ES were analyzed by flow cytometry after ex vivo stimulation with PMA/Ionomycin and intracellular cytokine staining. Graphical summary of the proportion of skin $\mathrm{CD} 4^{+} \mathrm{T}$ cells by gated $\mathrm{CD} 4^{+} \mathrm{CD} 3^{+} \mathrm{CD} 45^{+}$live leukocytes expressing IL17 and TNFa. $n=2-7 /$ experiment, cumulative data of 3 independent experiments. (circles=donor WT85, squares $=$ donor WT70, triangles $=$ WT73) Statistical significance determined by 2 -tailed unpaired student's $t$ test; mean \pm SD.

Antigen-specific T cell responses remain detectable in donor-mismatched skin tissue. These initial experiments were all performed using a completely matched system where ES, PBMC and moDC were from the same donor. However, access to skin that is matched to the PBMC of a specific patient group may present a limiting factor in studies of human cutaneous immune responses. To broaden the model's applicability, we sought to determine whether antigen-specific T cell responses could also be detected in the ES when we used donor-mismatched tissues. Therefore, we compared cutaneous $\mathrm{CD} 4^{+} \mathrm{T}$ cell responses to HKCA in donormatched and -mismatched ES. ES were generated from two different donors (donor A or B) designated ES-NSGA and ES-NSG-B. After complete wound healing, both recipients received PBMC that were either matched or mismatched to the ES and were injected intradermally with matched LPS/moDC or HKCA/moDC (i.e. the leukocyte populations were always HLA-matched) (Fig. 6a). The experiments were performed in both directions with $\mathrm{A}$ and $\mathrm{B}$ being either ES or leukocyte donor.

The proliferation of $\mathrm{CD}^{+} \mathrm{T}$ cells within allogeneic ES was slightly but not significantly increased compared to the fully matched system (Fig. 6b). Additionally, the levels of the activation maker HLA-DR ${ }^{65-67}$ were comparable within the allogeneic and the autologous ES in response to HKCA/moDC, and significantly increased compared to LPS/moDC injected ES (Fig. 6b). Similarly, CD4 ${ }^{+}$T cells within the ES injected with HKCA/ moDC secreted IL17 and TNFa compared to LPS/moDC, indicating C.albicans-specific activation of the T cells (Fig. 6c). Importantly, similar to HLA-DR the proportion of IFN $\gamma^{+} \mathrm{CD} 4^{+} \mathrm{T}$ cells were not increased within the allogeneic ES (Fig. 6c). Additionally, CD4:CD8 ratios remained unchanged between skin T cells from matched and mismatched HKCA/moDC injected ES suggesting a lack of CD8 expansion in response to the allogeneic keratinocytes and fibroblasts (Fig. 6d). Splenic CD4 ${ }^{+} \mathrm{T}$ cells showed no indication of an allogeneic response or HKCA-specific cytokine production (Fig. S8a-d) and, splenic $\mathrm{CD} 4^{+}: \mathrm{CD} 8^{+} \mathrm{T}$ cell ratios were unaltered in response to the allogeneic ES (Fig. S8e), indicating the absence of a systemic response. 
a
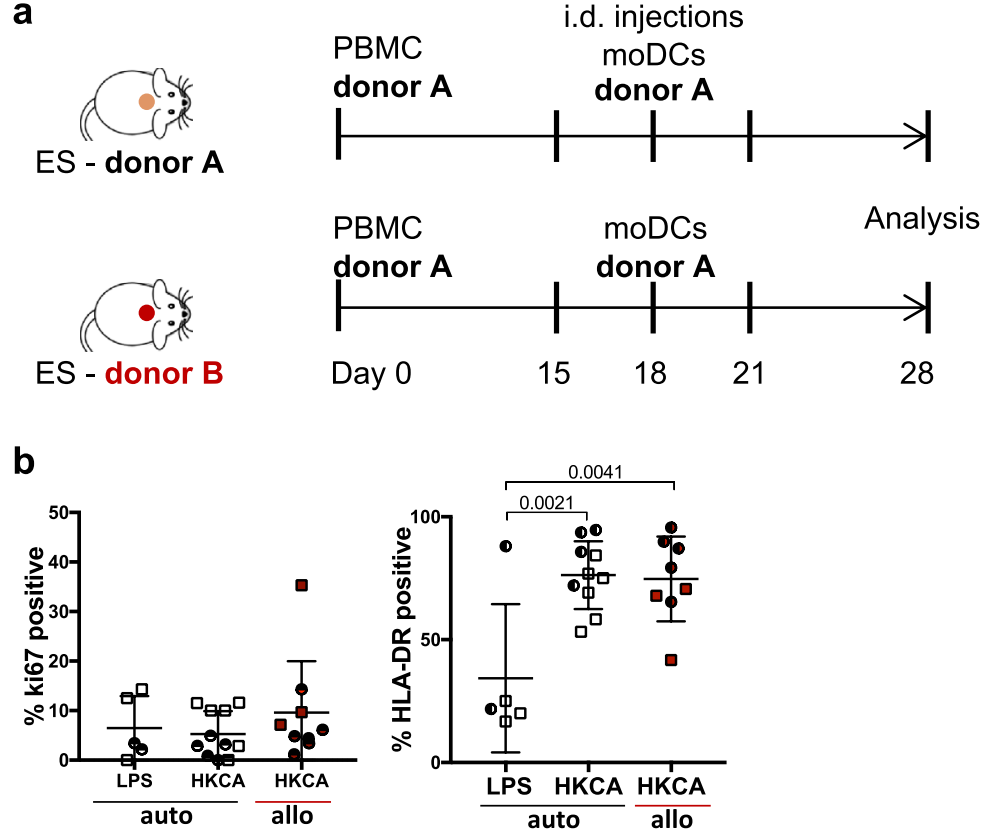

C
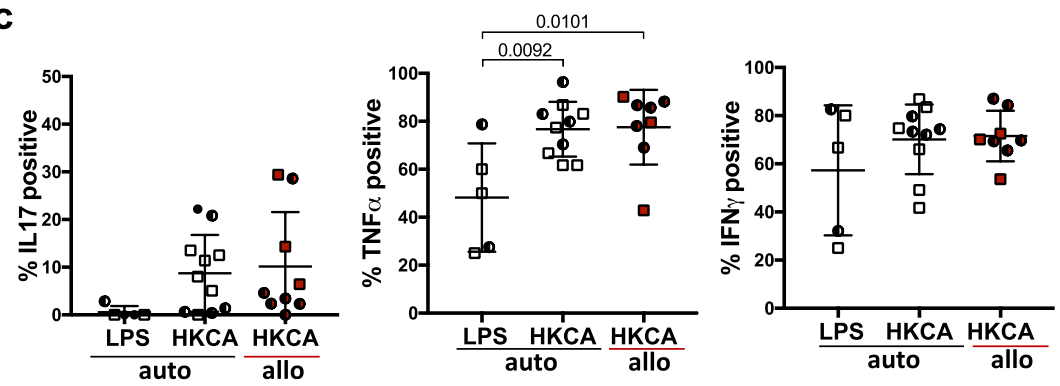

d

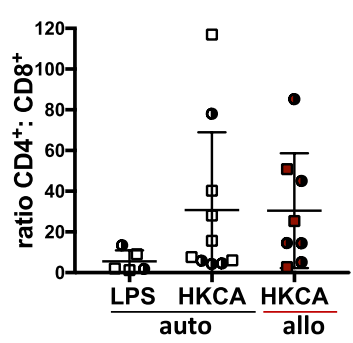

Figure 6. C. albicans-specific $\mathrm{CD} 4^{+} \mathrm{T}$ cell response can be detected in allogeneic ES. (a) Schematic: NSG mice bearing fully healed ES of one of two different skin donors (A and B) were adoptively transferred with either skin donor-matched PBMC or skin donor-mismatched PBMC. Intradermal injections of donor A derived LPS/ moDC or HKCA/moDC were performed as depicted (i.e. leukocytes were matched). Single cell suspensions of ES were analyzed by flow cytometry after ex vivo stimulation with PMA/Ionomycin and intracellular staining. $(\mathbf{b}, \mathbf{c})$ Graphical summary of the proportion of skin $\mathrm{CD} 4^{+} \mathrm{T}$ cells by gated $\mathrm{CD} 4^{+} \mathrm{CD} 3^{+} \mathrm{CD} 45^{+}$live leukocytes expressing the indicated markers following intradermal encounter of LPS/moDC (LPS) or HKCA/ moDC (HKCA). Red data points represent $\mathrm{CD} 4^{+} \mathrm{T}$ cells isolated out of mismatched ES. Statistical significance determined by ANOVA and Tuckey's test for multiple comparison; mean \pm SD. (d) Graphical summary of the ratio between $\mathrm{CD}^{+}$and $\mathrm{CD} 8^{+} \mathrm{T}$ cells of isolated skin $\mathrm{T}$ cells gated by $\mathrm{CD} 3^{+} \mathrm{CD} 45^{+}$live leukocytes. $\mathrm{n}=2-5$ / group, combined data of 2 independent experiments;

$\mathrm{CD4}^{+} \mathrm{T}$ cells isolated from ES respond to HKCA antigen ex vivo. To further confirm that the local activation and cytokine response of cutaneous $\mathrm{T}$ cells was truly antigen-specific rather than a non-specific response that was promoted by PMA/ionomycin stimulation, we isolated cutaneous T cells from ES that had been injected with HKCA/moDC, and then restimulated these cells ex vivo with moDCs that were either activated with LPS or loaded with HKCA in the presence of Brefeldin A (Fig. 7a). We found that re-stimulation with $\mathrm{HKCA} / \mathrm{moDCs}$ resulted in an increased fraction of proliferating Ki67 positive CD4 ${ }^{+} \mathrm{T}$ cells (Fig. $7 \mathrm{~b}$ ) and 
a

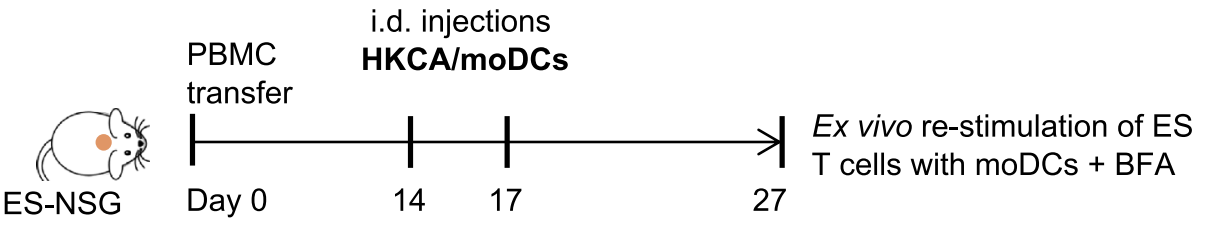

b

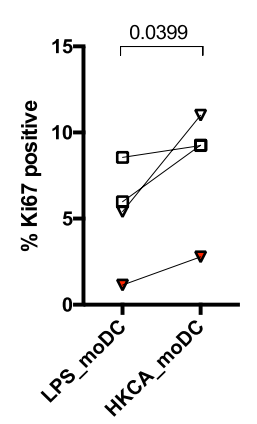

C

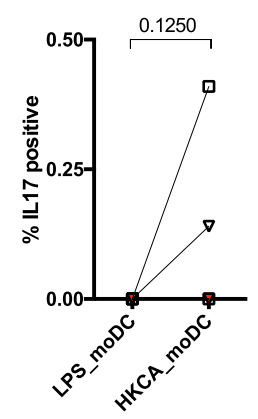

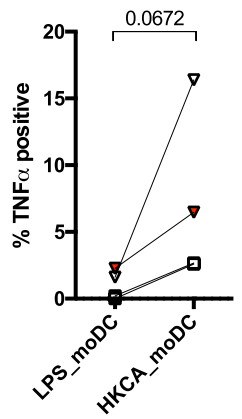

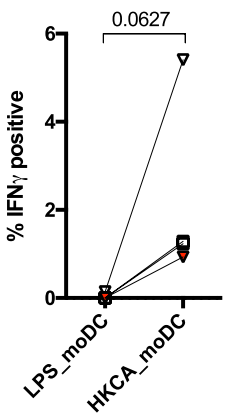

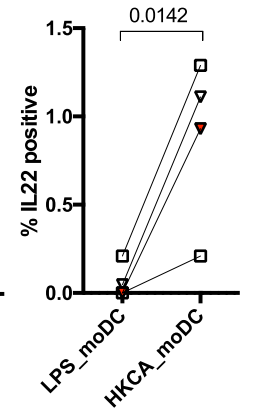

Figure 7. $\mathrm{CD}^{+} \mathrm{T}$ cell activation within the C. albicans injected ES grafts is antigen-specific. (a) Schematic of experimental procedure. Mice carrying ES received hPBMC followed by 1-2 intradermal injections of HKCAloaded moDCs autologous to the PBMC. 10 days after the last injection, single cell suspensions of ES were divided and re-stimulated ex vivo either with autologous moDCs stimulated with LPS or with moDC loaded with HKCA in presence of Brefeldin A (BFA) to detect cytokines by flow cytometry. (b) Graphical analysis of the proportion of $\mathrm{Ki} 67^{+}$proliferating cells of gated $\mathrm{CD} 4^{+} \mathrm{CD} 3^{+} \mathrm{CD} 45^{+}$live leukocytes from ES re-stimulated with LPS/moDC or HKCA/moDC. (c) Graphical summary of the proportion of CD4 ${ }^{+} \mathrm{T}$ cells from ES re-stimulated with LPS/moDC or HKCA/moDC producing the indicated cytokines. Combined data of 3 independent experiments $(n=3-11$ mice/experiment). Squares $=$ donor WT70, triangles $=$ WT73. Red data points represent $\mathrm{CD} 4^{+} \mathrm{T}$ cells isolated out of allo-mismatched ES. Clear symbols indicate autologous setting. Statistical significance determined by one tailed paired student's $t$ test.
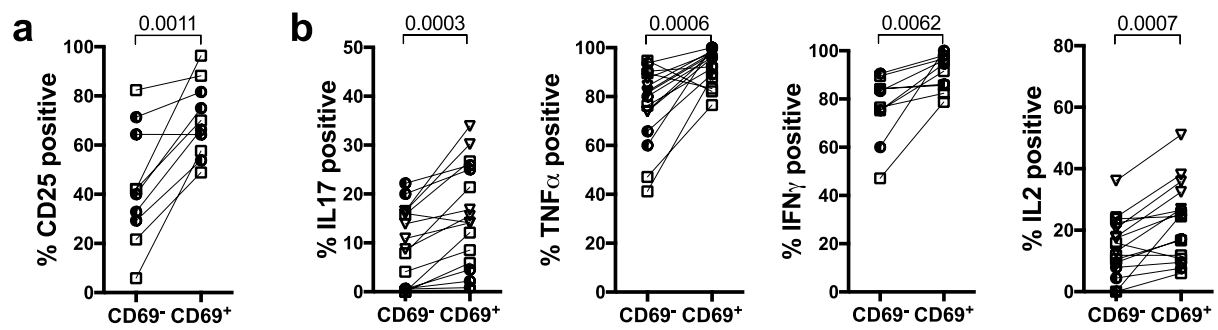

Figure 8. Cutaneous $\mathrm{CD} 4^{+} \mathrm{CD} 69^{+} \mathrm{T}$ Cells show increased effector function in response to C.albicans. Mice were treated as in Fig. 5. 7 days after the last injection of HKCA/moDC single cell suspensions were stimulated with PMA/ionomycin and analyzed by flow cytometry Graphical summary of the expression of (a) CD25 or (b) the indicated cytokines by $\mathrm{CD} 69^{-}$or $\mathrm{CD} 69^{+}$gated $\mathrm{CD} 4{ }^{+} \mathrm{CD} 3^{+} \mathrm{CD} 45^{+}$live leukocytes from ES. Each symbol represents an individual animal, donors: circles = donor WT85, squares=donor WT70, triangles =WT73; data from 2-3 experiments. Significance determined by paired student's $t$ test.

increased effector cytokine production compared to T cells that were re-stimulated with LPS/moDCs (Fig. 7c). These results indicate that the increased effector response of cutaneous T cells (observed in Figs. 5 and 6 ) is due to antigen-specific activation. Furthermore, we found that the injection of free HKCA (without moDCs) into the ES did not induce increased immune cell numbers or proliferation (read out as Ki67 ${ }^{+}$proportions), compared to the rate of $\mathrm{CD}^{+} \mathrm{T}$ cells that were stimulated with LPS/moDC (Fig. S7c). This indicates that the described response of $\mathrm{CD}^{+} \mathrm{T}$ cells in the HKCA/moDC group is dependent on antigen-presentation and not due to pathogen-associated signals present in HKCA.

Increased effector function of $\mathrm{CD} 69^{+} \mathrm{CD} 4^{+} \mathrm{T}_{\mathrm{RM}}$-like $\mathrm{T}$ cells in response to $C$.albicans. In a recent study it was shown that C.albicans specific responses in murine skin were mostly mediated by a population of cutaneous $\mathrm{CD} 69^{+} \mathrm{CD} 4^{+} \mathrm{T}_{\mathrm{RM}}$ cells generated after primary C.albicans infection, and a similar population was isolated from human $\operatorname{skin}^{16}$. Importantly, we identified a $\mathrm{CD} 69^{+}$population present within the ES prior to the 
encounter of C.albicans within the ES (Fig. 3e). We hypothesized that these newly established CD69 $9^{+} \mathrm{CD} 4^{+}$ memory-type $\mathrm{T}$ cells would show increased effector function upon antigenic challenge with the skin microbe C.albicans compared to the CD69- population, similar to what has been shown in human $\operatorname{skin}^{16}$. In line with these ex vivo findings, the $\mathrm{CD} 69^{+} \mathrm{CD} 4^{+} \mathrm{T}$ cell population isolated from ES that has been injected with $\mathrm{HKCA} /$ moDC showed superior effector function compared to the CD69- counterpart (Fig. 8). It remains to be determined whether this $\mathrm{CD} 69^{+} \mathrm{CD} 4^{+} \mathrm{T}_{\mathrm{RM}}$-like cell population was recruited upon application of $\mathrm{HKCA} / \mathrm{moDC}$ or seeded prior to C.albicans injection from the circulating pool of C.albicans specific T cells.

\section{Discussion}

Human skin contains a significant number of memory $\mathrm{T}$ cells that provide protective immunity and support tissue homeostasis $2,3,5,25,35$. The generation of cutaneous resident $\mathrm{T}_{\mathrm{RM}}$ cells at the site of primary infection has been studied using murine models ${ }^{6,7}$. However, suitable in vivo models to study human memory $\mathrm{T}$ cell generation, migration, and function of human cutaneous $\mathrm{T}$ cells to promote translational research were still lacking, and existing skin-humanized mouse models almost exclusively use allogeneic or inflammatory settings ${ }^{25,28,30,31}$. Fundamental insights revealing the heterogeneity of cutaneous human memory $\mathrm{T}$ cell subsets were gained recently by the group of Rachel Clark, when they investigated memory T cell populations in human skin in a xenograft skin mouse model. However, the infiltration of PBMC into the skin was driven by allogeneic MHC recognition of donor APCs contained in the skin graft ${ }^{25}$, thus reflected an inflammatory skin condition. To avoid the presence of resident immune cells within skin humanized mouse models, bioengineered skin combined with intradermal injection of in vitro generated $\mathrm{T}$ cell subsets and recombinant cytokines into the skin graft was used to study the pathogenesis of atopic dermatitis (AD) and psoriasis ${ }^{30,31}$. However, these models did not follow cutaneous functions of skin-tropic T cells (i.e. a memory sub-population specialized in cutaneous immunity) ${ }^{68-70}$. In health and disease, $\mathrm{T}$ cell recruitment to and function within the skin depends on a variety of skin-derived chemokines and cytokines ${ }^{5}$, and mutations leading to the loss of signaling result in impaired cutaneous $\mathrm{T}$ cell recruitment and/or maintenance ${ }^{38,51,52}$. Importantly, the ES we used ${ }^{41}$ reflected the chemokine environment found in healthy human skin, particularly chemokines and cytokines involved in T cell recruitment and activation, such as CCL $2^{46}$, $\mathrm{CCL}^{47}, \mathrm{CXCL} 10^{48}, \mathrm{CXCL} 12^{49}$ and T cell function and maintenance, like IL7 $7^{51,52}$ and IL1 $5^{51,53}$. In line with this, T cells migrated into the ES upon adoptive transfer of human PBMC, a process that was likely not driven by a tissue damage response, because the levels of inflammatory cytokines such as IL1 $\alpha, \operatorname{IL} 1 \beta$, TNFa, TNF $\beta$, IL18 and IL23 were lower or at equal levels in the ES when compared to healthy human skin. This highlights the power of the huPBMC-ES-NSG model to study human memory T cell migration and function in absence of acute inflammation, as well as the impact of tissue-derived signals on immunological processes in the skin. Importantly, the use of ES (i.e. human skin tissue without passenger leukocytes) permits precise control over the cell populations that partake in a specific immune response.

The ES was infiltrated by diverse subsets of memory $\mathrm{T}$ cells that maintained the multifunctional profiles of $\mathrm{T}$ cells found in human skin, and this was independent of the presence of APCs within the model. Importantly, $\mathrm{T}$ cells within the ES were functionally remarkably similar to T cells isolated from human skin, underlining the applicability of the huPBMC-ES-NSG model in studies of cutaneous T cell function in vivo. However, due to the increased proportion of GM-CSF secreting T cells in the system, which is likely the result of xenogeneic $\mathrm{T}$ cell activation within the model ${ }^{55,56}$, we expect that GM-CSF production would be a poor read-out for antigen-specific immune responses (e.g. against C.albicans). Thus, while GM-SCF plays an important role in anti-microbial immune responses ${ }^{56,71}$, we believe that our skin-humanized mouse model is not suitable to study the function and regulation of GM-CSF.

As in human subjects ${ }^{2}$, blood-derived skin-tropic $\mathrm{CLA}^{+} \mathrm{CD} 4^{+}$and $\mathrm{CD} 8^{+} \mathrm{T}$ cells accumulated within the skin when compared to splenic T cells and increased their expression of $\mathrm{T}_{\mathrm{RM}}$ markers, such as CD69 and CD103 ${ }^{15,25}$, underscoring the unique potential of this model to study the impact of tissue-derived factors on memory $\mathrm{T}$ cell generation.

It has been previously shown that in patients that had received intestinal allografts, recipient-derived graftinfiltrating CD69- $\mathrm{T}$ cells gave rise to long-lasting $\mathrm{CD} 69^{+} \mathrm{T}_{\mathrm{RM}}$ that replenished the total gut-resident $\mathrm{T}_{\mathrm{RM}}$ compartment ${ }^{72}$. A similar process of de novo $\mathrm{T}_{\mathrm{RM}}$ generation has been observed in patients that had received allogeneic lung transplants ${ }^{8}$. In line with that, the generation of $\mathrm{CD} 9^{+} \mathrm{T}_{\mathrm{RM}}$-like cells within the ES occurred from a pool of circulating $\mathrm{CD}^{-}{ }^{-} \mathrm{T}$ cells in absence of increased inflammatory cues or microbial antigen presentation within the ES.

Consistent with a population of C.albicans-specific cutaneous $\mathrm{CD} 69^{+} \mathrm{CD} 4^{+} \mathrm{T}_{\mathrm{RM}}$ cells isolated from human $\operatorname{skin}^{16}, \mathrm{CD} 9^{+} \mathrm{CD} 4^{+} \mathrm{T}$ cells responded more vigorously to injection of HKCA/moDCs into the ES. In fact, superior effector function of $C D 69^{+} \mathrm{T}_{\mathrm{RM}^{-}}$-like $\mathrm{T}$ cells has recently been shown for human $\mathrm{T}_{\mathrm{RM}}$ in various tissue sites ${ }^{21}$ when compared to the $\mathrm{CD} 69^{-} \mathrm{CD} 4^{+} \mathrm{T}$ cells. It remains to be determined whether this $\mathrm{CD} 69^{+} \mathrm{CD} 4^{+} \mathrm{T}_{\mathrm{RM}}$-like cell population was seeded prior to C.albicans injection from the circulating pool of C.albicans specific T cells. The fact that the model closely reflects the immunological response towards C.albicans makes it a formidable tool to study the dynamics and requirements of human cutaneous $\mathrm{T}_{\mathrm{RM}}$ function in vivo, that will potentially facilitate translational research in $\mathrm{T}_{\mathrm{RM}}$-mediated diseases.

We found that intradermal injection of moDCs loaded with antigen could substitute for poor engraftment of APC within the NSG model. Interestingly, antigen-specific T cell activation in response to HKCA presented by matched moDCs was detectable in both, autologous and allogeneic ES. Thus, access to matched blood and tissue samples might not be limiting the study of cutaneous $\mathrm{CD} 4^{+} \mathrm{T}$ cell responses in these skin-humanized mice.

Together, these data suggest that the huPBMC-ES-NSG model represents a suitable tool to study C.albicans specific local activation and memory responses of cutaneous $\mathrm{T}$ cells in vivo in a non-inflammatory setting. Importantly, the keratinocytes and fibroblasts used to generate ES can be cultured and manipulated using techniques 
such as CRISPR technology ${ }^{73}$. Thus, the huPBMC-ES-NSG model provides a highly versatile tool to study cutaneous $\mathrm{T}$ cell responses and to manipulate tissue-derived signals that impact skin immunity. Additionally, the model may serve as a platform to test novel therapeutic interventions to treat cutaneous inflammation, skin tumors or autoimmune diseases.

\section{Material and methods}

All methods were carried out in accordance with the relevant guidelines and regulations.

Mice. All animal studies were approved by the Austrian Federal Ministry of Science, Research and Economy. NOD.Cg-Prkdcscid Il2rgtm1Wjl/SzJ (NSG) mice were obtained from The Jackson Laboratory and bred and maintained in a specific pathogen-free facility in accordance with the guidelines of the Central Animal Facility of the University of Salzburg.

Human specimens. Normal human skin was obtained from patients undergoing elective surgery, in which skin was discarded as a routine procedure. Blood and/or discarded healthy skin was collected at the University Hospital Salzburg, Austria. Informed consent was obtained from all subjects. Samples of subjects of both sexes were included in the study. All studies were approved by the Salzburg state Ethics Commission (decision: according to Salzburg state hospital law no approval required) (Salzburg, Austria).

PBMC isolation for adoptive transfer into NSG recipients and flow cytometry. Human PBMC were isolated from full blood using Ficoll-Hypaque (GE-Healthcare; GE17-1440-02) gradient separation. PBMC were frozen in FBS with 10\% DMSO (Sigma-Aldrich; D2650), and before adoptive transfer thawed and rested overnight at $37^{\circ} \mathrm{C}$ and 5\% $\mathrm{CO}_{2}$ in RPMIc (RPMI 1640 (Gibco; 31870074) with 5\% human serum (Sigma-Aldrich; H5667 or H4522), 1\% penicillin/streptomycin (Sigma-Aldrich; P0781), 1\% L-Glutamine (Gibco; A2916801), 1\% NEAA (Gibco; 11140035), 1\% Sodium-Pyruvate (Sigma-Aldrich; S8636) and 0.1\% $\beta$-Mercaptoethanol (Gibco; 31350010). Cells were washed and 1.8-3 $\times 10^{6} \mathrm{PBMC} / \mathrm{mouse}$ intravenously injected. Female and male donors for adoptive transfer into huPBMC-NSG mice were aged 40-55 years.

Murine neutrophils were depleted with mLy6G (Gr-1) antibody (BioXcell; BE0075) intraperitoneally every 5-7 days as described before ${ }^{28}$.

Generation of engineered skin (ES). Human keratinocytes and fibroblasts were isolated from human skin and immortalized using human papilloma viral oncogenes E6/E7 HPV as previously described ${ }^{40}$. Three different skin donors were used: WT70 (indicated with square symbols in graphs), WT73 (triangles) and WT85 (circles). Cells were cultured in Epilife (Gibco, MEPICF500) or DMEM (Gibco; 11960-044) containing 2\% L-Glutamine,

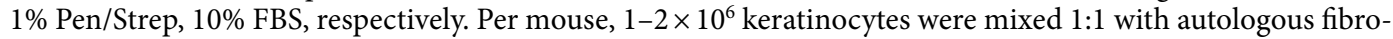
blasts in $400 \mu \mathrm{l}$ MEM (Gibco; 11380037) containing 1\% FBS, 1\% L-Glutamine and 1\% NEAA for in vivo generation of engineered skin as described ${ }^{41}$, with slight variations. Specifically, we used immortalized keratinocytes and fibroblasts, and the silicone grafting chambers were removed completely 7 days after transplantation.

T cell isolation from skin tissues for flow cytometry. Healthy human skin and ES were digested as previously described ${ }^{29}$. Approximately $1 \mathrm{~cm}^{2}$ of skin was digested overnight in $5 \% \mathrm{CO}_{2}$ at $37^{\circ} \mathrm{C}$ with $3 \mathrm{ml}$ of digestion mix containing $0.8 \mathrm{mg} / \mathrm{ml}$ Collagenase Type 4 (Worthington; \#LS004186) and $0.02 \mathrm{mg} / \mathrm{ml}$ DNase (Sigma-Aldrich; DN25) in RPMIc. ES were digested in $1 \mathrm{ml}$ of digestion mix. Samples were filtered, washed and stained for flow cytometry or stimulated for intracellular cytokine staining. Approx. $3 \mathrm{~cm}^{2}$ of shaved dorsal mouse skin were harvested and single cell suspensions prepared as described ${ }^{77}$ and stained for flow cytometry.

Generation of monocyte derived dendritic cells (moDC). moDC were generated from frozen PBMC similar to what has been described previously ${ }^{78}$. Briefly, PBMC were thawed and monocytes adhered for $75 \mathrm{~min}$ at $37^{\circ} \mathrm{C}$ and 5\% $\mathrm{CO}_{2}$ in DC medium (RPMI 1640: 10\% FBS, $2 \mathrm{mM} \mathrm{L-Glutamine,} 100 \mathrm{U} / \mathrm{ml}$ penicillin/streptomycin, $50 \mu \mathrm{M} \beta$-mercaptoethanol). After washing, adherent monocytes were cultured in DC medium supplemented with $50 \mathrm{ng} / \mathrm{ml}$ GM-CSF (ImmunoTools; 11343127) and $50 \mathrm{ng} / \mathrm{ml} \mathrm{IL4} \mathrm{(ImmunoTools;} \mathrm{11340047)} \mathrm{for} 7$ days to generate immature DC. After 6 days, cells were harvested and re-plated in DC medium without cytokines. For activation, moDCs were cultured for $9-13 \mathrm{~h}$ with $5 \mathrm{ng} / \mathrm{ml}$ LPS (Sigma-Aldrich; L2880) or $10^{6} \mathrm{cells} / \mathrm{ml}$ heat killed Candida albicans (eubio; tlrl-hkca). 1.8-3 $\times 10^{4} \mathrm{moDC} /$ mouse were intradermally injected in $50 \mu \mathrm{PBS} / \mathrm{mouse}$.

Antigen-specific re-stimulation of skin-derived T cells. Single cell suspension of ES pooled from multiple mice were divided into two equal parts and stimulated with LPS or HKCA loaded moDC autologous to the T cells for $20 \mathrm{~h}$, and $5 \mu \mathrm{g} / \mathrm{ml}$ Brefeldin A was added after $1 \mathrm{~h}$ of stimulation.

Flow cytometry. Cells were stained in PBS for surface markers. For detection of intracellular cytokine production, spleen and skin single cell suspensions and PBMC were stimulated with $50 \mathrm{ng} / \mathrm{ml}$ PMA (Sigma-Aldrich; P8139) and $1 \mu \mathrm{g} / \mathrm{ml}$ Ionomycin (Sigma-Aldrich; I06434) with $10 \mu \mathrm{g} / \mathrm{ml}$ Brefeldin A (Sigma-Aldrich; B6542) for 3.5 h. For permeabilization and fixation Cytofix/Cytoperm (BectonDickinson; RUO 554714) or Foxp3 staining kit (Invitrogen; 00-5523-00) were used. Data were acquired on LSR Fortessa (BD Biosciences) or Cytoflex LS (Beckman.Coulter) flow cytometers and analyzed using FlowJo software (Tree Star, Inc.) A detailed list of the used antibodies can be found in Supplementary Table S1

Histological staining of skin sections. Normal human skin, ES and adjacent murine skin were frozen in TissueTek (Sakura; TTEK). $7 \mu \mathrm{m}$ cryosections were stained with Hemalum solution acid (Carl Rorth; T865.1) and Eosin Y aqueous solution (Sigma, 201192A). Human type VII collagen was stained by immunofluorescence using anti-human type VII collagen antibody and goat anti-rabbit A488 as secondary antibody, ProLong ${ }^{\text {Ts }}$ Gold Antifade Mountant with DAPI, (Invitrogen; P36931) was used for nuclear staining and mounting. For immunohistochemistry paraffin-embedded normal human skin and ES was stained for human Cytokeratin 5/6 according to the manufacturer's protocol using a Ventana BenchMark Series automated slide stainer with ultraView Universal DAB Detection kit (Roche, 760-500).

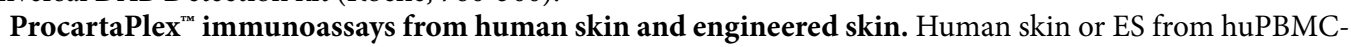
ES-NSG mice were stored at $-70^{\circ} \mathrm{C}$ until use. Skin was taken up in PBS with Protease Inhibitor Cocktail (1:100) 
(Sigma-Aldrich; P8340), homogenized and filtered through $0.22 \mu \mathrm{m}$ SpinX columns. Suspensions were stored at $-70^{\circ} \mathrm{C}$ until use. Samples were used at $8 \mathrm{mg} / \mathrm{ml}$ for assay. ProcartaPlex immunoassay was performed according to the manufacturer's protocol and measured using Luminex Magpix ${ }^{\oplus}$ system.

A detailed list of antibodies and reagents can be found in supplementary Table S1.

Statistical analysis. Statistical significance was calculated with Prism 7.0 software (GraphPad) by one-way ANOVA with Tukey's multiple comparisons test, or by paired or un-paired student's $t$ test as indicated. Error bars indicate mean \pm standard deviation. Statistical analyses were performed for all data sets and p-values indicated in the graph only when significant changes were observed.

Received: 20 May 2019; Accepted: 1 June 2020

Published online: 07 July 2020

\section{References}

1. Bos, J. D. et al. Predominance of 'memory' T cells (CD4+, CDw29+) over 'naive' T cells (CD4+, CD45R+) in both normal and diseased human skin. Arch. Dermatol. Res. 281, 24-30 (1989).

2. Clark, R. A. et al. The vast majority of CLA+ T cells are resident in normal skin. J. Immunol. Baltim. Md 1950(176), 4431-4439 (2006).

3. Nestle, F. O., Di Meglio, P., Qin, J.-Z. \& Nickoloff, B. J. Skin immune sentinels in health and disease. Nat. Rev. Immunol. 9, 679-691 (2009).

4. Di Meglio, P., Perera, G. K. \& Nestle, F. O. The multitasking organ: recent insights into skin immune function. Immunity 35, 857-869 (2011).

5. Klicznik, M. M., Szenes-Nagy, A. B., Campbell, D. J. \& Gratz, I. K. Taking the lead - how keratinocytes orchestrate skin T cell immunity. Immunol. Lett. 200, 43-51 (2018).

6. Gebhardt, T., Palendira, U., Tscharke, D. C. \& Bedoui, S. Tissue-resident memory T cells in tissue homeostasis, persistent infection, and cancer surveillance. Immunol. Rev. 283, 54-76 (2018).

7. Masopust, D. \& Soerens, A. G. Tissue-resident T cells and other resident leukocytes. Annu. Rev. Immunol. 37, 521-546 (2019).

8. Snyder, M. E. et al. Generation and persistence of human tissue-resident memory T cells in lung transplantation. Sci. Immunol. 4 , eaav5581 (2019).

9. Park, S. L. et al. Tissue-resident memory CD8+ T cells promote melanoma-immune equilibrium in skin. Nature 565, 366-371 (2019).

10. Campbell, J. J., Clark, R. A., Watanabe, R. \& Kupper, T. S. Sézary syndrome and mycosis fungoides arise from distinct T-cell subsets: a biologic rationale for their distinct clinical behaviors. Blood 116, 767-771 (2010).

11. Clark, R. A. et al. Skin effector memory T cells do not recirculate and provide immune protection in alemtuzumab-treated CTCL patients. Sci. Transl. Med. 4, 117ra7 (2012).

12. Casey, K. A. et al. Antigen independent differentiation and maintenance of effector-like resident memory T cells in tissues. J. Immunol. Baltim. Md 1950(188), 4866-4875 (2012).

13. Gebhardt, T. et al. Memory T cells in nonlymphoid tissue that provide enhanced local immunity during infection with herpes simplex virus. Nat. Immunol. 10, 524-530 (2009).

14. Glennie, N. D. et al. Skin-resident memory CD4+ T cells enhance protection against Leishmania major infection. J. Exp. Med. 212, 1405-1414 (2015).

15. Mackay, L. K. et al. The developmental pathway for CD103(+)CD8+ tissue-resident memory T cells of skin. Nat. Immunol. 14, 1294-1301 (2013).

16. Park, C. O. et al. Staged development of long-lived T-cell receptor $\alpha \beta$ TH17 resident memory T-cell population to Candida albicans after skin infection. J. Allergy Clin. Immunol. 142, 647-662 (2018).

17. Mackay, L. K. et al. T-box transcription factors combine with the cytokines TGF- $\beta$ and IL-15 to control tissue-resident memory $\mathrm{T}$ cell fate. Immunity $43,1101-1111$ (2015).

18. Pan, Y. et al. Survival of tissue-resident memory T cells requires exogenous lipid uptake and metabolism. Nature 543, 252-256 (2017).

19. Hu, W. \& Pasare, C. Location, location, location: tissue-specific regulation of immune responses. J. Leukoc. Biol. 94, 409-421 (2013).

20. McCully, M. L. et al. Epidermis instructs skin homing receptor expression in human T cells. Blood 120, 4591-4598 (2012).

21. Kumar, B. V. et al. Human tissue-resident memory T cells are defined by core transcriptional and functional signatures in lymphoid and mucosal sites. Cell Rep. 20, 2921-2934 (2017).

22. Gudjonsson, J. E., Johnston, A., Dyson, M., Valdimarsson, H. \& Elder, J. T. Mouse models of psoriasis. J. Investig. Dermatol. 127, 1292-1308 (2007).

23. Shay, T. et al. Conservation and divergence in the transcriptional programs of the human and mouse immune systems. Proc. Natl. Acad. Sci. 110, 2946-2951 (2013).

24. Perlman, R. L. Mouse models of human disease. Evol. Med. Public Health 2016, 170-176 (2016).

25. Watanabe, R. et al. Human skin is protected by four functionally and phenotypically discrete populations of resident and recirculating memory T cells. Sci. Transl. Med. 7, 279ra39 (2015).

26. King, M. A. et al. Human peripheral blood leucocyte non-obese diabetic-severe combined immunodeficiency interleukin-2 receptor gamma chain gene mouse model of xenogeneic graft-versus-host-like disease and the role of host major histocompatibility complex. Clin. Exp. Immunol. 157, 104-118 (2009).

27. Boyman, O. et al. Spontaneous development of psoriasis in a new animal model shows an essential role for resident $\mathrm{T}$ cells and tumor necrosis factor- $\alpha$. J. Exp. Med. 199, 731-736 (2004).

28. Racki, W. J. et al. NOD-scid IL2rgamma(null) mouse model of human skin transplantation and allograft rejection. Transplantation 89, 527-536 (2010).

29. Sanchez Rodriguez, R. et al. Memory regulatory T cells reside in human skin. J. Clin. Invest. 124, 1027-1036 (2014).

30. Carretero, M. et al. Differential features between chronic skin inflammatory diseases revealed in skin-humanized psoriasis and atopic dermatitis mouse models. J. Investig. Dermatol. 136, 136-145 (2016).

31. Guerrero-Aspizua, S. et al. Development of a bioengineered skin-humanized mouse model for psoriasis. Am. J. Pathol. 177, 3112-3124 (2010).

32. Boyce, S. T. et al. Skin anatomy and antigen expression after burn wound closure with composite grafts of cultured skin cells and biopolymers. Plast. Reconstr. Surg. 91, 632-641 (1993).

33. Burke, J. F., Yannas, I. V., Quinby, W. C., Bondoc, C. C. \& Jung, W. K. Successful use of a physiologically acceptable artificial skin in the treatment of extensive burn injury. Ann. Surg. 194, 413-428 (1981).

34. Nanchahal, J. \& Davies, D. Cultured composite skin grafts for burns. BMJ 301, 1342-1343 (1990).

35. Clark, R. A. Resident memory T cells in human health and disease. Sci. Transl. Med. 7, 269rv1 (2015). 
36. Jiang, X. et al. Skin infection generates non-migratory memory CD8+ T(RM) cells providing global skin immunity. Nature $\mathbf{4 8 3}$, 227-231 (2012).

37. Campbell, J. J. \& Butcher, E. C. Chemokines in tissue-specific and microenvironment-specific lymphocyte homing. Curr. Opin. Immunol. 12, 336-341 (2000).

38. Nowak, K. et al. Absence of $\gamma$-chain in keratinocytes alters chemokine secretion, resulting in reduced immune cell recruitment. J. Investig. Dermatol. 137, 2120-2130 (2017).

39. Uchi, H., Terao, H., Koga, T. \& Furue, M. Cytokines and chemokines in the epidermis. J. Dermatol. Sci. 24, S29-S38 (2000).

40. Merkley, M. A. et al. Large-scale analysis of protein expression changes in human keratinocytes immortalized by human papilloma virus type 16 E6 and E7 oncogenes. Proteome Sci. 7, 29 (2009).

41. Wang, C. K., Nelson, C. F., Brinkman, A. M., Miller, A. C. \& Hoeffler, W. K. Spontaneous cell sorting of fibroblasts and keratinocytes creates an organotypic human skin equivalent. J. Investig. Dermatol. 114, 674-680 (2000).

42. Wetzels, R. H. W., Robben, H. C. M., Leigh, I. M., Vooijs, G. P. \& Ramaekerst, F. C. S. Distribution patterns of type VII collagen in normal and malignant human tissues. Am. J. Pathol. 139, 451-459 (1991).

43. Ali, N. et al. Xenogeneic graft-versus-host-disease in NOD-scid IL-2R $\gamma$ null mice display a T-effector memory phenotype. PLoS ONE 7(8), e44219 (2012).

44. King, M. et al. A new Hu-PBL model for the study of human islet alloreactivity based on NOD-scid mice bearing a targeted mutation in the IL-2 receptor gamma chain gene. Clin. Immunol. Orlando FL 126, 303-314 (2008).

45. Shultz, L. D. et al. Human lymphoid and myeloid cell development in NOD/LtSz-scid IL2R pnull mice engrafted with mobilized human hemopoietic stem cells. J. Immunol. 174, 6477-6489 (2005).

46. Carr, M. W., Roth, S. J., Luther, E., Rose, S. S. \& Springer, T. A. Monocyte chemoattractant protein 1 acts as a T-lymphocyte chemoattractant. Proc. Natl. Acad. Sci. USA 91, 3652-3656 (1994).

47. Kawai, T. et al. Selective diapedesis of Th1 cells induced by endothelial cell RANTES. J. Immunol. Baltim. MD 1950(163), 3269-3278 (1999).

48. Fukui, A. et al. Interleukin-8 and CXCL10 expression in oral keratinocytes and fibroblasts via Toll-like receptors. Microbiol. Immunol. 57, 198-206 (2013).

49. Nanki, T. \& Lipsky, P. E. Stimulation of T-Cell activation by CXCL12/stromal cell derived factor-1 involves a G-protein mediated signaling pathway. Cell. Immunol. 214, 145-154 (2001).

50. Moser, B. \& McCully, M. L. The human cutaneous chemokine system. Front. Immunol. 2, 33 (2011).

51. Adachi, T. et al. Hair follicle-derived IL-7 and IL-15 mediate skin-resident memory T cell homeostasis and lymphoma. Nat. Med. 21, 1272-1279 (2015).

52. Belarif, L. et al. IL-7 receptor blockade blunts antigen-specific memory $\mathrm{T}$ cell responses and chronic inflammation in primates. Nat. Commun. 9, 1-13 (2018).

53. Wang, X. et al. Engraftment of human central memory-derived effector CD8+ T cells in immunodeficient mice. Blood 117, 1888-1898 (2011).

54. Klicznik, M. M. et al. Human CD4+CD103+ cutaneous resident memory T cells are found in the circulation of healthy individuals. Sci. Immunol. 4(37), eaav8995 (2019).

55. Shannon, M. F., Himes, S. R. \& Coles, L. S. GM-CSF and IL-2 share common control mechanisms in response to costimulatory signals in T cells. J. Leukoc. Biol. 57, 767-773 (1995).

56. Shi, Y. et al. Granulocyte-macrophage colony-stimulating factor (GM-CSF) and T-cell responses: what we do and don't know. Cell Res. 16, 126-133 (2006).

57. Belkaid, Y. \& Tamoutounour, S. The influence of skin microorganisms on cutaneous immunity. Nat. Rev. Immunol. 16, 353-366 (2016).

58. Gosselin, A. et al. Peripheral blood CCR4+CCR6+ and CXCR3+CCR6+CD4+ T cells are highly permissive to HIV-1 infection. J. Immunol. Baltim. MD 1950(184), 1604-1616 (2010).

59. Klein, R. S. et al. Oral candidiasis in high-risk patients as the initial manifestation of the acquired immunodeficiency syndrome. N. Engl. J. Med. 311, 354-358 (1984).

60. Lagunes, L. \& Rello, J. Invasive candidiasis: from mycobiome to infection, therapy, and prevention. Eur. J. Clin. Microbiol. Infect. Dis. Off. Publ. Eur. Soc. Clin. Microbiol. 35, 1221-1226 (2016).

61. Ling, Y. et al. Inherited IL-17RC deficiency in patients with chronic mucocutaneous candidiasis. J. Exp. Med. 212, 619-631 (2015).

62. Puel, A. et al. Chronic mucocutaneous candidiasis in humans with inborn errors of interleukin-17 immunity. Science 332, 65-68 (2011).

63. Acosta-Rodriguez, E. V. et al. Surface phenotype and antigenic specificity of human interleukin 17-producing T helper memory cells. Nat. Immunol. 8, 639-646 (2007).

64. Hernández-Santos, N. \& Gaffen, S. L. Th17 cells in immunity to Candida albicans. Cell Host Microbe 11, 425-435 (2012).

65. Holling, T. M., Schooten, E. \& van Den Elsen, P. J. Function and regulation of MHC class II molecules in T-lymphocytes: of mice and men. Hum. Immunol. 65, 282-290 (2004).

66. Oshima, S. \& Eckels, D. D. Selective signal transduction through the CD3 or CD2 complex is required for class II MHC expression by human T cells. J. Immunol. Baltim. Md 1950(145), 4018-4025 (1990).

67. Ko, H. S. IA determinants on stimulated human T lymphocytes. Occurrence on mitogen- and antigen-activated T cells. J. Exp. Med. 150, 246-255 (1979).

68. Duhen, T., Geiger, R., Jarrossay, D., Lanzavecchia, A. \& Sallusto, F. Production of interleukin 22 but not interleukin 17 by a subset of human skin-homing memory T cells. Nat. Immunol. 10, 857-863 (2009).

69. Schlapbach, C. et al. Human TH9 cells are skin-tropic and have autocrine and paracrine proinflammatory capacity. Sci. Transl. Med. 6, 219ra8-219ra8 (2014).

70. Zielinski, C. E. et al. Pathogen-induced human TH17 cells produce IFN- $\gamma$ or IL-10 and are regulated by IL-1 $\beta$. Nature 484, 514-518 (2012).

71. Fidan, I. et al. The effects of fluconazole and cytokines on human mononuclear cells. Mem. Inst. Oswaldo Cruz 102, 127-131 (2007).

72. Zuber, J. et al. Bidirectional intragraft alloreactivity drives the repopulation of human intestinal allografts and correlates with clinical outcome. Sci. Immunol. 1(4), eaah3732 (2016).

73. Fenini, G. et al. Genome editing of human primary keratinocytes by CRISPR/Cas9 reveals an essential role of the NLRP1 inflammasome in UVB sensing. J. Investig. Dermatol. 138, 2644-2652 (2018).

74. Farber, D. L., Yudanin, N. A. \& Restifo, N. P. Human memory T cells: generation, compartmentalization and homeostasis. Nat. Rev. Immunol. 14, 24-35 (2014).

75. Saule, P. et al. Accumulation of memory T cells from childhood to old age: central and effector memory cells in CD4(+) versus effector memory and terminally differentiated memory cells in CD8(+) compartment. Mech. Ageing Dev. 127, 274-281 (2006).

76. Haynes, L. \& Swain, S. L. Why aging T cells fail: implications for vaccination. Immunity 24, 663-666 (2006).

77. Gratz, I. K. et al. Cutting edge: self-antigen controls the balance between effector and regulatory T cells in peripheral tissues. J. Immunol. Baltim. Md 1950(192), 1351-1355 (2014).

78. Sallusto, F. \& Lanzavecchia, A. Efficient presentation of soluble antigen by cultured human dendritic cells is maintained by granulocyte/macrophage colony-stimulating factor plus interleukin 4 and downregulated by tumor necrosis factor alpha. J. Exp. Med. 179, 1109-1118 (1994). 


\section{Acknowledgements}

We especially thank all human subjects for blood and skin donation and the nurses at the Breast Center University Hospital of the Paracelsus Medical University Salzburg, Austria. We thank Dr. Stefan Hainzl, EB House Austria, Department of Dermatology, University Hospital of the Paracelsus Medical University Salzburg, Austria, for the immortalization of primary human keratinocytes and fibroblasts. We thank Monika Prinz from the Department of Dermatology at the University Hospital of the Paracelsus Medical University Salzburg, Austria for help with the IHC staining and Peter Steinbacher from the Department of Biosciences at the University of Salzburg, Austria, for support with microscopy. This work was supported by the Focus Program "ACBN" of the University of Salzburg, Austria, by a grant from the Dystrophic Epidermolysis Bullosa Research Association (DEBRA) International and DEBRA Austria, and NIH Grant R01AI127726. M.M.K is part of the PhD program Immunity in Cancer and Allergy, funded by the Austrian Science Fund (FWF, Grant W 1213) and was recipient of a DOC Fellowship of the Austrian Academy of Sciences.

\section{Author contributions}

I.K.G., E.M.M., M.D.R., D.J.C. and M.M.K. conceptualized the study, M.M.K., E.M.M. and I.K.G. designed the experiments; M.M.K., A.B., L.M.G., S.R.V. and R.H. acquired the data; M.L. performed I.H.C. staining, ASt, R.R., and A.S. acquired human samples, T.N. and J.H.-H. helped establish the moDC cultures and performed quality control; M.M.K. performed data analysis, M.M.K. and I.K.G. interpreted the data and wrote the manuscript. All authors reviewed the final version of the manuscript. I.K.G and E.M.M supervised the project.

\section{Competing interests}

M.M.K., E.M.M. and I.K.G. are inventors on patent application EP18168258 / US 16389821 that was jointly filed by the University of Salzburg, Austria, and Debra Austria that covers the use of skin humanized mice in pre-clinical studies involving engineered skin and human T cells.

\section{Additional information}

Supplementary information is available for this paper at https://doi.org/10.1038/s41598-020-67430-7.

Correspondence and requests for materials should be addressed to I.K.G.

Reprints and permissions information is available at www.nature.com/reprints.

Publisher's note Springer Nature remains neutral with regard to jurisdictional claims in published maps and institutional affiliations.

Open Access This article is licensed under a Creative Commons Attribution 4.0 International License, which permits use, sharing, adaptation, distribution and reproduction in any medium or format, as long as you give appropriate credit to the original author(s) and the source, provide a link to the Creative Commons license, and indicate if changes were made. The images or other third party material in this article are included in the article's Creative Commons license, unless indicated otherwise in a credit line to the material. If material is not included in the article's Creative Commons license and your intended use is not permitted by statutory regulation or exceeds the permitted use, you will need to obtain permission directly from the copyright holder. To view a copy of this license, visit http://creativecommons.org/licenses/by/4.0/.

(C) The Author(s) 2020 